Against this hypothesis, Garrod maintains, are (1) his experiments on the effects of temperature; like other disinfectants, penicillin is more active at higher temperatures, but is even more active at $42^{\circ} \mathrm{C}$., when bacterial growth ceases, than at $37^{\circ} \mathrm{C}$.; incidentally, Garrod finds that its action is impaired by increase of the acidity between $p \mathrm{H} 7 \cdot 0$ and $5 \cdot 0$ (2) the fact that bacteria from both old and very young cultures are almost uniformly susceptible. Garrod therefore thinks that there is no conclusive evidence in support of Bigger's proposal to give penicillin intermittently, and claims that clinical experience supports his view. Penicillin treatment fails because the organisms are inaccessible inside necrotic areas or in undetected abscesses.

Further important conclusions drawn by Garrod are that nothing is to be gained by using higher concentrations of penicillin (cf. Sir A. Fleming, Lancet, 621, Nov. 11, 1944; see also Nature, 155, 341, March 17, 1945), especially in local treatment. The idea that higher doses will be more effective does not apply to penicillin. The reverse is truer. A concentration of 1 unit per c.c. is not only just as effective as one of 1,000 units, but is often more effective. The only good reason for using stronger solutions in local treatment is to ensure that the concentration does not fall below the minimum fully effective level of about $0 \cdot 1$ unit per c.c. Garrod further emphasizes the importance of the purity of the penicillin which is being used experimentally. He found that all commercial penicillins tested were less active in higher than in low concentrations. Presum. ably impurities were responsible for this, and they cause serious obstacles to the study of the action of penicillin. It will be necessary to find out whether penicillin is a single substance of unvarying composition and uniform action.

Discussing these results in a valuable leading article, the British Medical Journal (123, Jan. 27, 1945) directs attention to the enormous variation in the susceptibility of various bacteria to penicillin. Some species classed as totally resistant are affected by higher concentrations of penicillin; for example, the typhoid bacillus and the salmonellas. H. F. Helmholz and C. Sung (Amer. J. Dis. Children, 68, 236 ; 1944) have found that some resistant bacteria in the urine are affected by high concentrations, for example, Proteus and some strains of B. coli. Only Bact. aerogenes and Pseudomonas pyocyanea remained unaffected. The treatment of some infections of the urinary tract with penicillin might thus be effective. E. W. Todd, G. S. Turner and L. G. W. Drew (Brit. Med.J., 111, Jan. 27, 1945) have found that Staphylococcus strain Oxford $H$. can be trained by growth in increasing quantities of penicillin to become 3,000 times more resistant to penicillin than it originally was. Similar results were obtained with another strain of Staphylococcus. Unlike other organisms which become 'drug-fast', however, Staphylococcus lost this property rapidly in media not containing penicillin. The authors refer to work which showed, on the other hand, that pneumococcus type III, made resistant to penicillin, either by culture in media containing penicillin (G. Rake et al., J. Immunol., 48, $271 ; 1944$ ) or by passage through mice treated with penicillin (L. H. Schmidt and C. L. Sesler, Proc. Soc. Expt. Biol., N.Y., 52, $353 ; 1943)$, retained its resistance. The nature of these phenomena of resistance requires further investigation. Although some organisms can produce a penicillinase which destroys penicillin (see, for example, the penicillinase produced by $B$. subtilis reported by E. S. Duthie, Brit. $J$. Expt. Path., 25, 96 ; 1944), resistance to penicillin apparently does not always depend on the production by the resistant organism of penicillinase. W. M. Kirby (Science, 452, June 2, 1944) has extracted a substance which is not penicillinase from Staphylococcus resistant to penicillin.

G. LAPAGE.

\section{INDIAN FOREST YIELD TABLES}

E. VER since the Forest Research Institute came into being at Dehra Dun (1907), the Sylvicultural Branch set out to obtain data for the preparation of volume and yield tables for some of the more important timbers such as teak, sal, and deodar, to mention but three of the best known throughout India. Selected sample plots of varying type and age had been previously formed by the forest officer in different parts of India, and more or less periodically measured and records kept. But for the most part the work was spasmodic and a proportion at least of the data obtained of doubtful usefulness.

As a result of the work inaugurated, attempts were made to prepare yield tables, among others, for the sal (Shorea robusta); such a table was prepared by Smythies and Howard and published in 1923. It was based on the measurements of some fifty-two plots of sal, chiefly in the United Provinces, with a few in Bengal and the Central Provinces. The sal has a wide distribution from the foothills and neigh. bouring border in the plains in the United Provinces as far west as the Jumna River, eastwards along this line through Nepal and Bengal Duars into Assam as far as Tezpur, its eastern boundary. To the south it is found in the eastern part of the Central Provinces and in Chota Nagpur, south-western Bengal, Orissa Province and Orissa Feudatory States to Ganjam in the Madras Provinces. It thus is equally at home in a dry hot as well as in a damp hot climate, and grows on a variety of soil conditions. Since the above tables were published, many more data have been collected, and this information has been collated in Indian Forest Records (Sylviculture) New Series, "Yield and Stand Tables for Sal (Shorea robusta) High Forest" (4.A., No. 4, Model Press, Delhi, 1943) by M. L. Griffith, sylviculturist, and Bakhshi Sant Ram. The present tables are based on 542 measurements from 225 sample plots in twenty-five forest divisions of five provinces. Sample plot selection, upkeep and measurements in the different provinces are now greatly facilitated by the existence in the provinces of provincial sylvicultural research officers whose investigations and results are available to the Central Research Institute. That this departure is of the highest value is evidenced by the authors' remark, "The tables now produced are admittedly not completely satisfactory on account of the abnormality of some of the basic data. The main difficulties arose through inconsistent thinning procedure. These have been described in more detail together with the methods attempted to overcome them."

Just as the progress in ordered management of a forest department is indicated by the number of the forests which have been placed under working plans, including the type of plan in force, so the degree to which sylvicultural work has advanced is evidenced by the possibility of being able to prepare suitable yield and stand tables for use in the forests under management. 